\title{
Implementation of Solar Power with Smart Grid
}

\author{
Rishi Sikka
}

\begin{abstract}
This paper focus on the work that is to explore Photovoltaic and Power Supply techniques in Smart Grid Energy Management. The research document also aims to foster an understanding of the concept and benefits of Smart Grid. The research work includes a comprehensive literature review to identify the key findings in the Sun Energy amplification range with Smart Grid Systems. As part of this research, Smart Grid's place has been described for spreading solar energy generation. Research work also aims to assess different ways to put the Smart Grid model into the Sun Energy exchange system, explaining Solar PV requirements for Smart Grid applications.
\end{abstract}

Keywords- photovoltaic panel, solar power plant, smart grid management.

\section{INTRODUCTION}

The present grid is dated (almost all of them are designed and installed before the microprocessors) and suffer from reliability issues [1]. The grid has controlled and accelerated updated in a slow speed around the distance of technological advances [2],[3]. This is largely the result of large infrastructure investment that was under way. However, Smart Grid technologies require real change in this area. Smart Grid provides the bilingual communication for electricity transmission and therefore incorporates the concept of controlled demand forecast and electricity generation [4]. The benefits of a smart grid can be strengthened through the integration of non-conventional energy resources such as Wind, Biomass power plants and solar. Solar power takes the visible place among all other sources because it receives its continued and cost effectiveness. hence much of the investigation and growth activity in smart clearance is ongoing [5]. The education institutions and international corporations are working hard on tackling the clean grid concepts and the use of unusual energy to the green earth environment for the future. The idea of a smart grid is to unite the Information Technology and Electrical Electricity to benefit consumers as well as industry [6],[7].

"A smart grid is a system that is adaptive, interactive, secured, supports bi-directional energy flow and has no geographical or organizational boundaries".[8]

The advantages of smart grid system are; [9]

- Better and smart metering reliability.

- Improvement in the operation of electrical apparatus

- Continuity in the power supply from source to load without any interruption.

- Uninterruptedly monitoring the power transported and power consumption statistics throughout.

Revised Manuscript Received on 14 September, 2019.

Rishi Sikka, Department of Electronics Engineering, Sanskriti University, Uttar Pradesh, India.(Email: sanpubip@gmail.com) and power quality of the power system.

- Connecting and synchronizing all the renewable energy resources with the grid for fulfilling the energy demand of the customers.

\section{MODELING OF SMART GRID SYSTEM INTEGRATED WITH SOLAR PANEL}

The dynamic model is designed and simulated for a photovoltaic generating system. The improved system comprises of a solar PV module [10], a dc / dc converting device with a transformer device. designed for the MPP to be carried out by reference control (Iref), are manufactured by $\mathrm{P} \& \mathrm{O}$ algorithm, an asynchronous generator, and a double rectifier, and dc to ac thyristor.

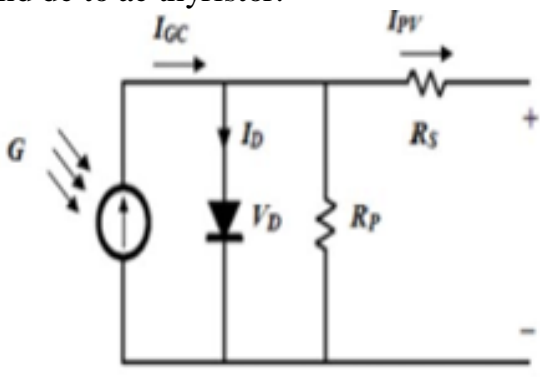

Fig l: Single diode PV cell equivalent circuit

Fig.1 shows the equivalent circuit of PV system [11], it includes photodiode, series and shunt resistance. The equation of current flow through the circuit is given by;

$$
I_{p v}=I_{g c}-I_{o}\left[\exp \left(\frac{e v_{d}}{K F T_{c}}\right)-1\right]-\frac{v_{d}}{R_{p}}
$$

Where,

$\mathrm{Igc}=$ generated current.

Io $=$ saturation current.

$\mathrm{Rp}=$ parallel or shunt resistance.

$\mathrm{Vd}=$ voltage of diode .

$$
I_{g c}=\left[\mu_{s c}\left(T_{c}-T_{r}\right)+I_{s c}\right] G
$$

The modified form of above equation is given by-

$$
\begin{aligned}
& I_{o}=I_{o \propto}\left(\frac{T_{c}}{T_{r}}\right)^{3} \exp ^{\left\lfloor\frac{e v_{g}}{K F}\left(\frac{1}{T_{r}}-\frac{1}{T_{c}}\right)\right\rfloor} \\
& I_{o \alpha}=\frac{I_{s c}}{\exp ^{\left(\frac{e v_{o c}}{K T_{o}}\right)}}
\end{aligned}
$$


In this review a standard PV module has been design and applied in MATLAB / SIMULINK to determine non-linear product features for the PV module. The proposed module is employed which is represented in fig. 2

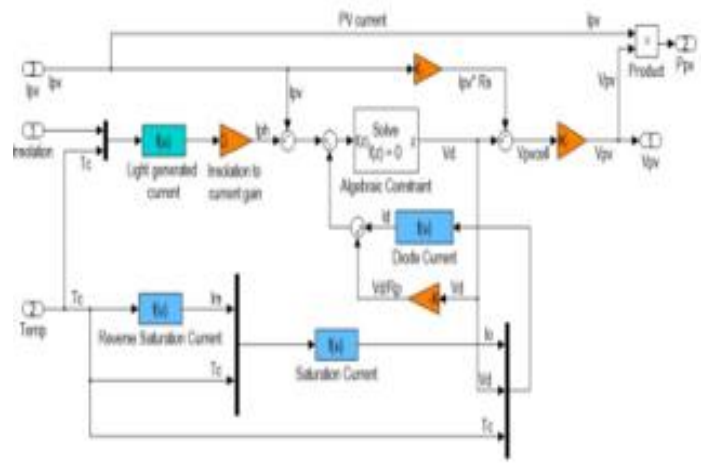

Fig 2: Subsystem implementation of PV model

The PV module has a non-linear output characteristic for the irradiation sunlight falling on the PV module. In addition, the solar energy falling on the surface is not reliable due to irradiation, which is the greatest cause of reducing level of power generation from PV module.

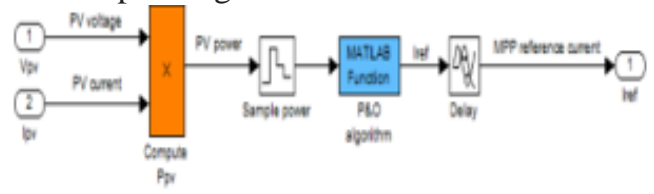

Fig 3: Subsystem implementation of the MPPT controller model

Hence for obtaining high efficiency the electronic based controller known as maximum power point tracker is employed for pull out the maximum power [12]. The algorithm known as perturb and observe is coded in the MATLAB Simulink software. this algorithm increases and decrease the power of the PV module according to the needs of the customer. It senses the output voltage and current of the photovoltaic module and if the value of voltage and current is less than the desired value, maximum power point tracker controller will boost up the voltage and current and gives the output in a boosted form.

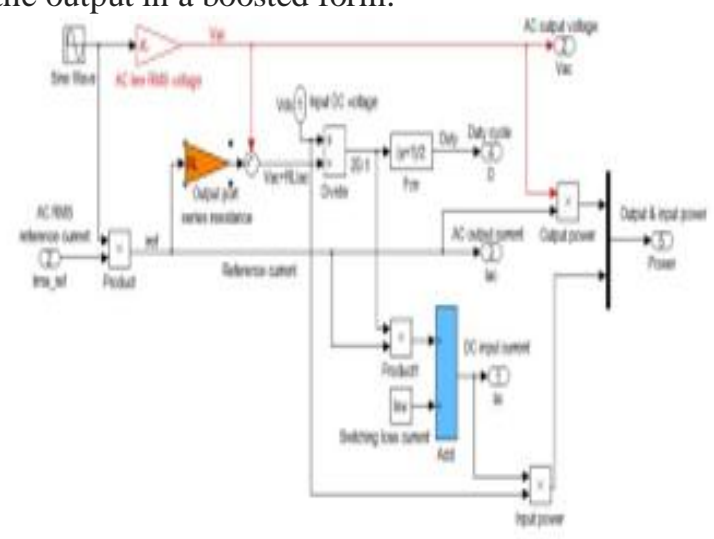

Fig 4: Subsystem implementation of the de/ac inverter model

Moreover, for eliminating the switching harmonics and boosting up the output voltage of PV module to the higher value of voltage the switch converter is implemented in MATLAB simulation which is shown in fig. 4 . the automatic feedback controller is required to make the dc voltage constant and balancing the power. The block diagram of proposed system is shown in fig. 5

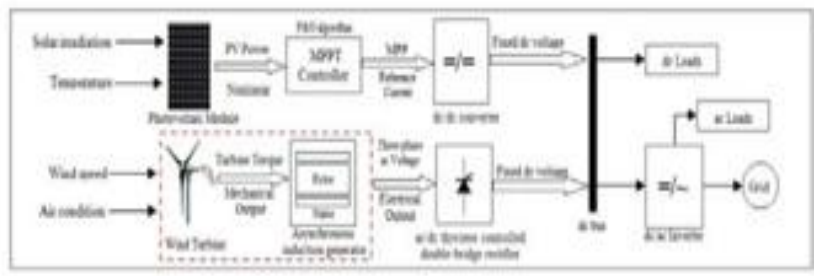

Fig 5: Block diagram of proposed system

\section{RESULT}

Fig. 2 represents the implementation of PV module on the subsystem. For improving the conversion efficiency of solar PV module, the maximum power point tracker (MPPT) is employed in the subsystem which is shown in fig.3. after stepping up the dc power through the MPPT the boosted power is transferred to dc to ac inverter shown in fig. 4 and the drawing of planned system is represented in fig.5.

\section{CONCLUSION}

The main purpose of proposed system is to develop the smart grid system which is combined with the solar panels. The complete model is design and implemented in MATLAB simulation. The solar module is combined with smart grid to reduce the uncertainty of power flow and balancing the power supply from source to load. In smart grid, additional power source in the form of solar PV module is applied in the distribution system so that there is a continuity of power even if the primary source is cut out.

\section{REFERENCES}

1. C. Wan, J. Zhao, Y. Song, Z. Xu, J. Lin, and Z. Hu, "Photovoltaic and solar power forecasting for smart grid energy management," CSEE J. Power Energy Syst., 2016.

2. B. V. Mathiesen et al., "Smart Energy Systems for coherent $100 \%$ renewable energy and transport solutions," Applied Energy. 2015.

3. K. S. Reddy, M. Kumar, T. K. Mallick, H. Sharon, and S. Lokeswaran, "A review of Integration, Control, Communication and Metering (ICCM) of renewable energy based smart grid," Renewable and Sustainable Energy Reviews. 2014.

4. L. Zhang, N. Gari, and L. V. Hmurcik, "Energy management in a microgrid with distributed energy resources," Energy Convers. Manag., 2014.

5. X. Liu, P. Wang, and P. C. Loh, "A hybrid AC/DC microgrid and its coordination control," IEEE Trans. Smart Grid, 2011.

6. W. Qi, J. Liu, and P. D. Christofides, "A distributed control framework for smart grid development: Energy/water system optimal operation and electric grid integration," J. Process Control, 2011.

7. M. Bouzguenda, A. Gastli, A. H. Al Badi, and T. Salmi, "Solar photovoltaic inverter requirements for smart grid applications," in 2011 IEEE PES Conference on Innovative Smart Grid Technologies - Middle East, ISGT Middle East 2011, 2011. 
8. H. Farhangi, "Smart Grid," in Encyclopedia of Sustainable Technologies, 2017.

9. X. Fang, S. Misra, G. Xue, and D. Yang, "Smart grid The new and improved power grid: A survey," IEEE Communications Surveys and Tutorials. 2012.

10. V. Sharma and S. S. Chandel, "Performance and degradation analysis for long term reliability of solar photovoltaic systems: A review," Renewable and Sustainable Energy Reviews. 2013.

11. G. E. Jellison and P. C. Joshi, "Crystalline silicon solar cells," in Springer Series in Optical Sciences, 2018.

12. M. A. M. Ramli, S. Twaha, K. Ishaque, and Y. A. AlTurki, "A review on maximum power point tracking for photovoltaic systems with and without shading conditions," Renewable and Sustainable Energy Reviews. 2017. 